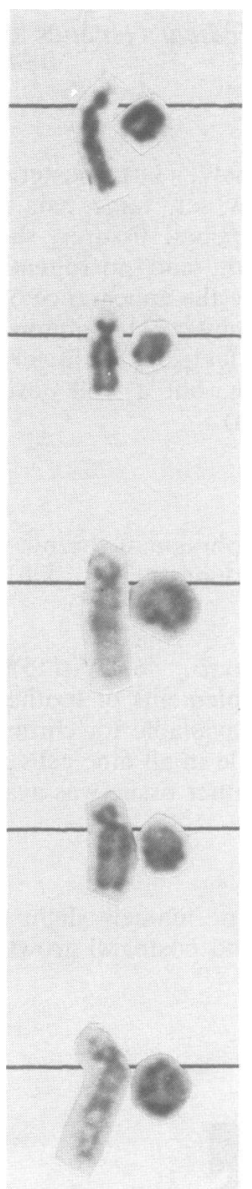

FIG $2 G$ banded partial karyotype of the ring chromosome $r(15)(q 26 \rightarrow q t e r)$ and its normal homologue.

facies, and short hands and feet, has been associated with ring chromosome $15 .^{1}$ Two thirds of published cases had few or no dysmorphic stigmata, but growth failure and survival seemed to be the rule. ${ }^{2}$

Recently two sibs (a liveborn infant and a 13 week fetus) with a $(15 \mathrm{q} 24 \rightarrow$ qter $)$ deletion, both with diaphragmatic hernias and lung hypoplasia, were reported. ${ }^{3}$ The first infant was slightly dysmorphic with low set ears, club feet, and cryptorchidism, and was small for gestational age. The fetus had one umbilical artery and dysplastic kidneys.

All the physical features of our patient, except the growth failure and absence of nail hypoplasia, have been noted in Fryns' syndrome. No chromosome abnormalities have been reported in other cases of Fryns' syndrome. Growth failure is present in $20 \%$ of our neonates, but the patient's appearance is incompatible with his ancestry and suggests a syndromal component. The questions arise of whether the anomalies of diaphragmatic hernia, dysplastic kidneys, and dysmorphism are the result of the ring $15 \stackrel{?}{=}$ and whether this patient has Fryns' syndrome. The latter is a rare syndrome, not yet reported from this country. If the $\overrightarrow{0}$ patient has Fryns' syndrome, could this be the result of monosomy of the recessive gene on the morphologically normal chromosome?

The authors wish to thank the Cape Provincial Administra- $\frac{0}{\infty}$ tion, the South African Medical Research Council, and the University of Stellenbosch for their support. The secretarial . assistance of Mrs M Page is gratefully acknowledged. We would like to thank $\operatorname{Dr} M$ Nelson for reviewing the $\omega$ manuscript and for helpful suggestions.

G DE JoNG, R A Rossouw, AND

A E Retief ? $M R C$ Research Unit for Cytogenetics, it Medical School, $\searrow$ University of Stellenbosch, Tygerberg,

Republic of South Africa.

\author{
References \\ ${ }^{1}$ Fryns JP, Timmermans J, D'Hondt F, Francois B, Emmery L, \\ Van den Berghe $\mathrm{H}$. Ring chromosome 15 syndrome. Hum Genet \\ 1979;51:43-8. \\ 2 Kosztolányi G, Pap M. Severe growth failure associated with \\ atrophic intestinal mucosa and ring chromosome 15. Acta \\ Paediatr Scand 1986;75:326-31. \\ 3 Kristoffersson U, Hein S, Mandahl N, Sundkvist L, Szelest J, \\ Hägerstrand I. Monosomy and trisomy of $15 \mathrm{q} 24 \rightarrow$ qter in a \\ family with a translocation $t(6 ; 15)(p 25 ; q 24)$. Clin Genet 1987 \\ 32:169-71.
}

Correspondence to Dr G de Jong, MRC Research Unit for Cytogenetics, Medical School, University of Stellenbosch, PO Box 63, Tygerberg, Republic of South Africa.

\section{Unknown syndrome: Noonan-like craniofacial features, digital anomalies, and premature birth}

SUMMARY We report a mother and two of her children, one female and the other male, who have ptosis, hypertelorism, epicanthic folds, downward slanting palpebral fissures, broad nasal bridge, and minor digital anomalies (fig 1); the children had delayed closure of a large anterior fontanelle. All three affected persons were born prematurely.

\section{History}

The normally intelligent mother was born six weeks prematurely when her father was aged 33 years, and was 
thought to resemble neither her parents nor her four healthy sibs who were born at term. As a teenager spontaneous pneumothorax was treated by pleurodesis. Her first pregnancy was uncomplicated until premature rupture of membranes and spontaneous onset of labour at 28 weeks' gestation. The female proband's birth weight was on the 50th centile. Respiratory distress syndrome was treated by artificial ventilation and patent ductus arteriosus closed by indomethacin. Osteitis of the femur at one month of age was treated with antibiotics. In her second pregnancy spontaneous onset of labour occurred at 31 weeks and the male infant's birth weight was on the 50th centile. He had mild respiratory distress. Her third pregnancy went to term when a normal male infant was born.

\section{Clinical examination}

Proband: at 12 weeks chronological age, downward slanting palpebral fissures, hypertelorism, large anterior fontanelle. At four years three months, height 50 th centile, weight 25 th centile, OFC 75 th centile, prominent forehead, ptosis, epicanthic folds, hypertelorism (IPD $=60$ $\mathrm{mm},>97$ th centile), hypermetropic astigmatism, strabismus, entropion, persistent hyaloid artery, unilateral hearing loss, broad nasal bridge, fifth finger clinodactyly, and dysplastic toenails. Joint laxity was present at the knee and finger joints. Psychomotor and speech delay present in the first three years resolved so that detailed psychological assessments at four and a half years placed her within normal ranges. Normal Giemsa banded female karyotype in blood lymphocytes.

Affected male sib: at three years, height 3rd centile, weight 3 rd centile, OFC 3 rd centile, prominent forehead, two strawberry naevi, unilateral ptosis, downward slanting palpebral fissures, epicanthic folds, hypertelorism (IPD $=55 \mathrm{~mm},>97$ th centile), broad nasal bridge, short nose, long philtrum (75th centile), fifth finger clinodactyly, left inguinal hernia (repaired), and dysplastic toenails. Joint laxity detected at the knee and finger joints.

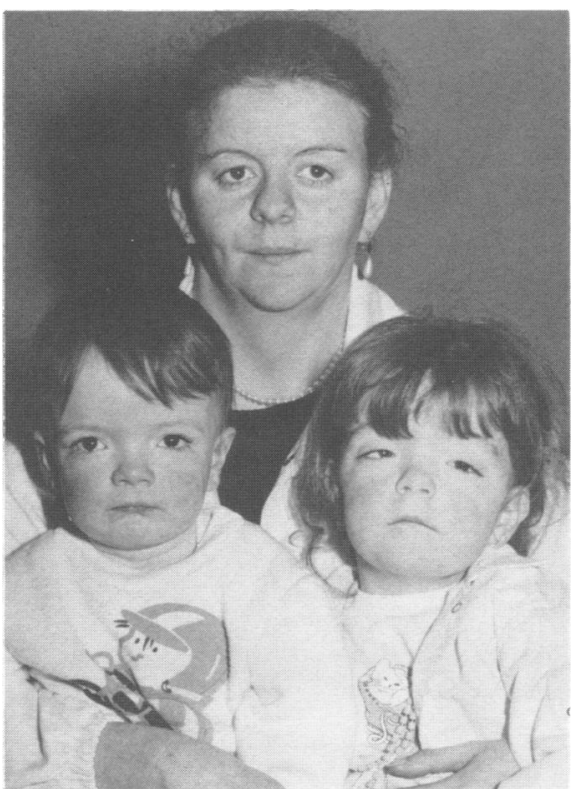

FIG 1 The proband aged four and a half years, her affected brother aged three years, and their mother. Note that the impression of hypertelorism in the mother pictured in infancy (fig 2) is not present in adulthood.

Developmental progress similar to that of his sister with diminishing evidence of psychomotor delay as he gets older.

Proband's mother: facial features in childhood (fig 2) similar to her affected children; she was also 'loose jointed' as a child but lost this trait in adulthood. Normal intelligence, height 25 th centile, weight 25 th centile, OFC

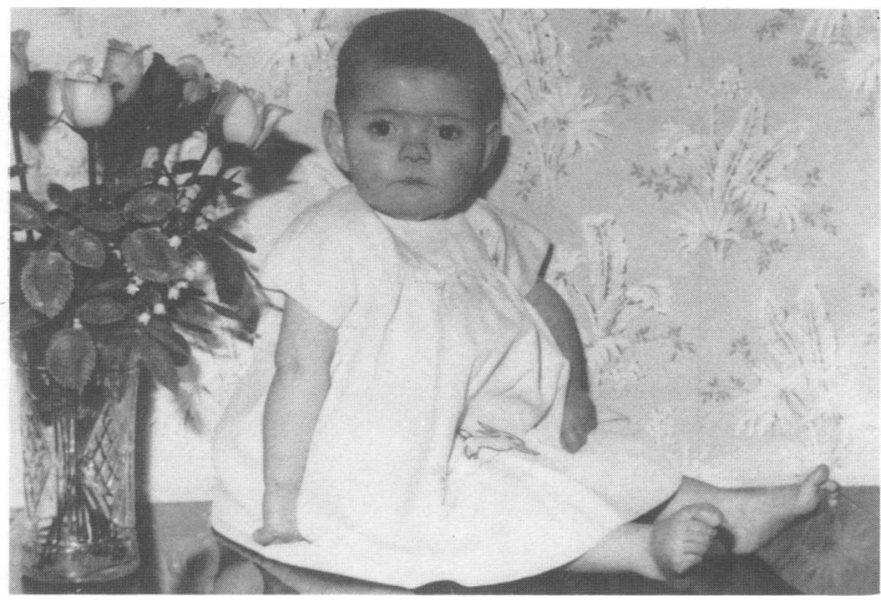

FIG 2 The mother as an infant. 


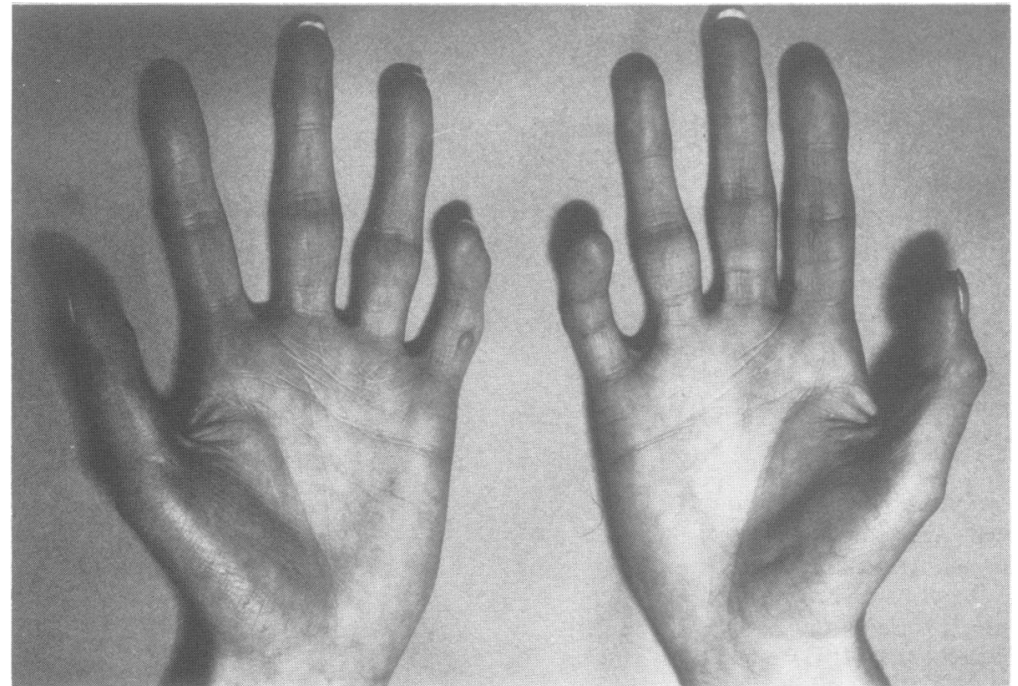

FIG 3 The mother's hands showing slender fingers, camptodactyly and clinodactyly of the fifth digit, and the postaxial remnant.

3rd centile, slight left ptosis, downward slanting palpebral fissures, slender fingers, clinodactyly and camptodactyly of the fifth finger with unilateral postaxial remnant (fig 3), dysplastic toenails.

\section{Discussion}

Ptosis, hypertelorism, downward slanting palpebral fissures, and digital anomalies may be present together in Aarskog's syndrome and Noonan's syndrome. However, other features of these conditions (cardiac defects, short stature, ear and genital anomalies) were absent in this family and thus it seems likely that this craniofacial phenotype is non-specific; for example, there are reports of autosomal dominant ${ }^{1}$ and autosomal recessive ${ }^{2}$ conditions mimicking Aarskog's syndrome. The occurrence of premature birth and a degree of joint laxity in each affected subject is interesting and may indicate an underlying connective tissue disorder even though the skin was normal. It would seem worthwhile to investigate collagen biosynthesis in this family.

\section{References}

${ }^{1}$ Grier RE, Farrington FH, Kendig R, Mamunes P. Autosomal dominant inheritance of Aarskog syndrome. Am J Med Genet 1983;15:39-46.

2 Teebi AS, Naguib KK, Al-Awadi SA, Al-Saleh QA. New autosomal recessive faciodigitogenital syndrome. J Med Genet $1988 ; 25: 400-6$

R Cameron Shepherd, D R Goudie, AND J L TOLMIE

Department of Paediatrics, Inverclyde Royal Hospital, Larkfield Road, Greenock; and

Duncan Guthrie Institute of Medical Genetics, Yorkhill Hospitals, Yorkhill, Glasgow.

Correspondence to Dr R C Shepherd, Department of 옥 Paediatrics, Inverclyde Royal Hospital, Larkfield Road, Greenock PA16 0XN, Scotland. 